\title{
The effect of structure and degree of tilt on the tilted room illusion
}

\author{
G. SINGER AND A. T. PURCELL, ${ }^{1}$ MACQUARIE UNIVERSITY \\ MARGARET AUSTIN, UNIVERSITY OF NEW SOUTH WALES
}

The effect of structure and angle of tilt on the magnitude of the tilted-room illusion and its relationship to the illusion produced by a tilted-line field were examined in two experiments. In Experiment 1, nine groups of $13 \mathrm{Ss}$ were tested under three conditions of room tilt in the frontal plane $122.5,45$, and $67.5 \mathrm{deg})$ and under three conditions of structure (empty room, room with a back wall of stripes, and room with furniture). The results indicate that, while magnitude and direction of the illusion vary with degree of room tilt, structure increases the magnitude of the illusion only at a 45-deg room tilt. In Experiment 2, a field of lines was presented through a circular reduction tube to three groups of $13 \mathrm{Ss}$ under three conditions of line tilt $(22.5,45$, and $67.5 \mathrm{deg})$. An illusion occurred that was much smaller in magnitude and functionally different for the three tilt conditions when compared with the tilted-room illusion.

Asch and Witkin $(1948 a, b)$ and Witkin and Asch (1948a, b) demonstrated that exposing an $S$ to any of a variety of frameworks tilted in the frontal plane resulted in errors in judgment of the vertical in the direction of the tilt of the framework. ${ }^{2}$ Austin, Singer, and Day (1969) exposed Ss to a tilted room and found that, with repeated judgments of the vertical in the presence of the room, the magnitude of the error in judgment increased over trials, and further, that the error in judgment persisted after a time lapse (15 min) during which a purely sensory aftereffect would have dissipated. Together with the 22.5-deg room tilt Asch and Witkin had employed, Austin et al (1969) exposed Ss to 45- and 67.5-deg tilts. The effect was found to increase over trials with all room tilts; however, the rate of increase and the variance among Ss was greatest at 45 deg.

One question that is posed by these studies concerns the determinants of the size of this illusion. Witkin and Asch (1948b) commented, in relation to their experiments with a tilted frame, a tilted

Fig. 1a. Stimulus configuration for the Gibson tilted-line illusion.

Fig. 1b. Tilted room showing furniture and the striped back wall. mirror, and a tilted room, that the differences in the size of the effect with these varying frameworks was possibly due to the variations in articulation, naturalness, and number of verticals and horizontals contained in these fields. The tilted frame has the simplest structure, the room contains more verticals and horizontals together with familiar objects, and the mirror allows the $S$ to see a more natural, structured environment.

This approach appears to assume that the mirror transformation, the tilted room, and the rod and frame all produce the same effect, differing only in the relative magnitude of the illusions that they produce. Also, it is possible that the two factors suggested by Asch and Witkin-the number of horizontals and verticals and the presence of familiar objects-are either the determinants of the size of the illusion in all cases or the determinants of the illusion itself.

The experiment reported here attempts to assess the effect of these two factors on the size of the illusion in one of the above situations, the tilted room. The room without any additions was employed as a baseline condition with two experimental conditions. The first increased the number of verticals in the field by adding to the back wall of the room a field of black-and-white stripes. The second was designed to assess the effect of familiar objects or cognitive structure by the addition of furniture to the room. As the direction and magnitude of the tilted-room illusion was shown by Austin et al (1969) to vary with the extent of rotation, within each of the above experimental conditions, independent groups were run at tilt angles of $22.5,45$, and $67.5 \mathrm{deg}$.

Further, it can be seen that the visual display, when black-and-white stripes are added to the room, contains components that are similar to the Gibson tilted-line illusion (Gibson \& Radner, 1937). Logan (1962) has shown that the magnitude and the direction of this illusion varies as a function of the tilt of the background lines and, therefore, may have made varying contributions to the effect of increasing the number of verticals in the room. In a second experiment, therefore, a field identical to that added to the room was presented through a reduction tube, at angles of $22.5,45$, and $67.5 \mathrm{deg}$, to three groups of Ss.

\section{METHOD}

The apparatus and procedures for the two experiments were essentially the same and are described together.

\section{Apparatus}

The dimensions of the room were $4 \times 4 \times 4 \mathrm{ft}$. The room was mounted on a stand that allowed rotation through $360 \mathrm{deg}$ in the frontal plane. The inside of the room was painted flat white and was illuminated by a $60-\mathrm{W}$ globe placed on the ceiling. On the back wall of the room was a 16-in.-long, 1-in.-wide bar painted with luminous paint and placed slightly above the center point of the room. The bar was pivoted at its center and could be rotated by turning a handle located to the S's right when he was seated in front of the room. A
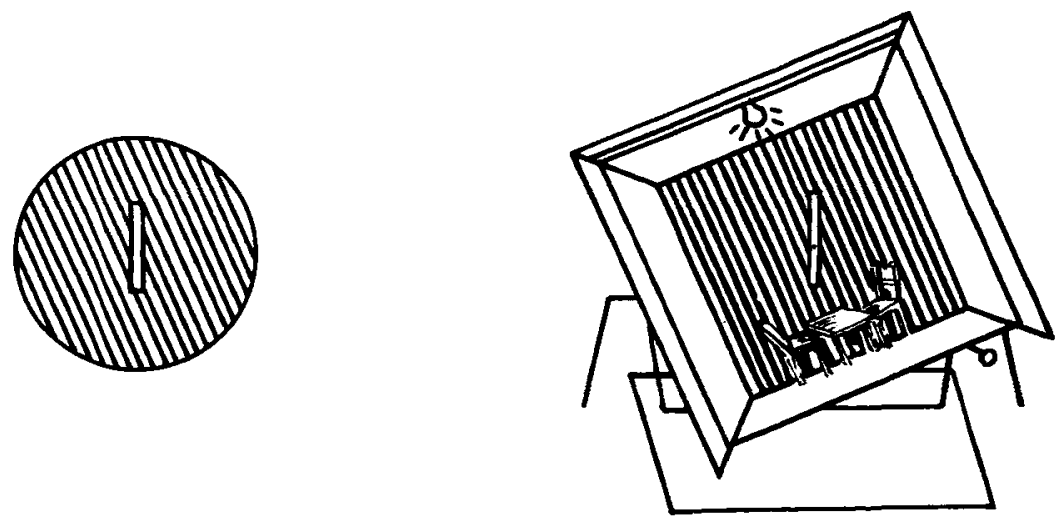

Fig. 1A
Fig. 1B 
protractor mounted behind the room enabled S's judgments to be read directly in degrees as deviations from the zero point. A white blind fixed on the roof of the room could be lowered by the $\mathrm{E}$ to occlude S's view of the room between trials. A small table and two chairs were fixed centrally to the floor of the room for the room-plus-furniture conditions, and a 4-ft square board painted with 1 -in. (wide) black and 2-in. (wide) white stripes (parallel with the walls of the room) was fixed to the back wall of the room for the room-plus-stripes and the tilted-line illusion conditions (see Figs. 1a and 1b).

\section{Subjects}

Twelve groups of 13 Ss were drawn from 1st year psychology courses at Macquarie University.

\section{Procedure}

In the first experiment, the $S$ was met outside the laboratory, led in wearing opaque-lensed rubber goggles, seated on a chair, and positioned directly in front of and $4 \mathrm{ft}$ from the bar to be judged. The basic procedure and the method of rotating the bar was explained to $S$. Then the laboratory lights were turned off, the goggles were removed, and testing commenced immediately. Binocular viewing was employed in both experiments. The experimental procedure involved 2 pretest judgments of the vertical in the dark and 10 judgments of the vertical with the room illuminated. Ss were instructed to rotate the bar until it looked vertical to them. Between judgments, the S's view of the room and the bar was occluded by the blind.

For the tilted-line illusion experiment (Experiment 2), the procedure was exactly the same, except that a reduction tube was mounted on the front of the room. The reduction tube presented to the $S$ a circular field of view $4 \mathrm{ft}$ in diam (see Fig. 1a); thus, the overall size of the S's visual field was exactly the same as in the first experiment, except that the corners of the room were eliminated. The striped patterns for inducing the illusion were the same as those employed in the room-plus-stripes condition of the first experiment.

In both experiments, nine starting positions of the bar were employed and were randomized across Ss. All of the room and stripe tilts were counterclockwise, and a setting of the bar deviating from true vertical in the direction of the room or stripe tilt was scored as positive and judgments in the opposite direction as negative.

\section{RESULTS}

The results of the two experiments (which are shown in Tables $1 \mathrm{a}$ and $1 \mathrm{~b}$ ) were analyzed separately using a modification of Grant's (1956) trend analysis. Planned comparisons (Rodger, 1965) between room and furniture and room alone (RF vs RA) and between room and furniture and room and stripes (RF vs RS) for both means and linear trend components at each angle of tilt of the room were then tested. The estimate of error variance used was the mean square between individual means or individual linear trend components, respectively. Similarly planned comparisons for means and linear trend components were carried out on the basis of a similar analysis of the second experiment, contrasts for means and linear components at 22.5 and $67.5 \mathrm{deg}$ being tested against the same value for $45 \mathrm{deg}$. The means, linear components, estimates of the error variance, and contrasts are presented in Tables $1 \mathrm{a}$ and $1 \mathrm{~b}$.

\section{DISCUSSION}

As can be seen from Table 1a, an increase in the cognitive structure (the addition of fumiture to the room) or an increase in the number of verticals in the visual field (the addition of stripes) does not increase the mean illusion or alter the rate of growth of the illusion (as indexed by the linear component) except when the room is tilted $45 \mathrm{deg}$. Here, the presence of either the furniture or stripes increases both the mean illusion and its rate of growth when compared to the room alone.

The explanation for these effects is difficult to find. The diagonal, although not judged as accurately as the vertical or horizontal, is judged more accurately than any other angular rotations from these positions. This could account for the lower mean illusion in the room-alone condition when compared to 22.5 - or $67.5-\mathrm{deg}$ room tilts (6 deg as compared to 14 or $12 \mathrm{deg}$ ). It could be hypothesized that the stripes and furniture increase the illusion by preventing such increased accuracy of judgment. From these results, it can be argued that, at least for tilts of 22.5 and $67.5 \mathrm{deg}$, neither structure nor the number of verticals in the field appears to be the primary determinant of the size of the illusion. In these latter conditions, it appears that a maximum illusion is reached in the room alone. Further, on the basis of Experiment 2, it can be seen that the increase in the illusion at $45 \mathrm{deg}$ as a result of the addition of more verticals to the room cannot be explained simply in terms of the Gibson tilted-line illusion, no such illusion being found with line tilts of $45 \mathrm{deg}$. It can also be seen that, although the illusions with line fields at 22.5 and $67.5 \mathrm{deg}$ are in the same direction as the room illusion, it would appear to be impossible to explain the mean illusion under all three conditions as being examples of a Gibson tilted-line illusion.

Table 1A

Mean Illusions, Trend Components and Contrasts Tested in Experiment 1 (Tilted Room)

\begin{tabular}{|c|c|c|c|c|c|c|c|}
\hline \multicolumn{2}{|c|}{ Group } & $\begin{array}{c}\text { Mean } \\
\text { Illusion } \\
\text { (Degrees) }\end{array}$ & $\begin{array}{c}\text { Linear } \\
\text { Component } \\
\text { (Tan. } \theta)\end{array}$ & $\begin{array}{c}\text { Contrasts } \\
\text { (Means) }\end{array}$ & $\mathbf{F}$ & $\begin{array}{c}\text { Contrasts } \\
\text { (Linear } \\
\text { Component) }\end{array}$ & $\mathbf{F}$ \\
\hline $45 \mathrm{Deg}$ & $\begin{array}{l}\text { Furniture } \\
\text { Stripes } \\
\text { Alone }\end{array}$ & $\begin{array}{r}17.063 \\
13.127 \\
5.894\end{array}$ & $\begin{array}{l}1.057 \\
1.025 \\
0.256\end{array}$ & $\begin{array}{l}F-A^{*} \\
F-S(N S)\end{array}$ & $\begin{array}{r}19.27 \\
2.39\end{array}$ & $\begin{array}{l}F-A^{*} \\
F-S(N S)\end{array}$ & $\begin{array}{l}5.84 \\
0.01\end{array}$ \\
\hline $22.5 \mathrm{Deg}$ & $\begin{array}{l}\text { Furniture } \\
\text { Stripes } \\
\text { Alone }\end{array}$ & $\begin{array}{l}14.683 \\
12.400 \\
13.873\end{array}$ & $\begin{array}{l}0.072 \\
0.332 \\
0.278\end{array}$ & $\begin{array}{l}F-A(N S) \\
F-S(N S)\end{array}$ & $\begin{array}{l}0.10 \\
0.81\end{array}$ & $\begin{array}{l}F-A(N S) \\
F-S(N S)\end{array}$ & $\begin{array}{l}0.39 \\
0.62\end{array}$ \\
\hline $67.5 \mathrm{Deg}$ & $\begin{array}{l}\text { Furniture } \\
\text { Stripes } \\
\text { Alone } \\
\end{array}$ & $\begin{array}{r}-9.535 \\
-12.512 \\
-11.769 \\
\end{array}$ & $\begin{array}{l}-0.453 \\
-0.404 \\
-0.330\end{array}$ & $\begin{array}{l}F-A(N S) \\
F-S(N S)\end{array}$ & $\begin{array}{l}0.77 \\
1.37\end{array}$ & $\begin{array}{l}F-A(N S) \\
F-S(N S)\end{array}$ & $\begin{array}{l}0.10 \\
0.05\end{array}$ \\
\hline
\end{tabular}

df 1,108-MS between individual means (error) $=420.760$

$M S$ between individual linear trend components (error) $=58.693$

* Contrasts significant at the 0.05 level

Critical value of $F_{0.05}=3.90$

Table 1B

Mean Illusions, Trend Components and Contrasts Tested in Experiment 2 (Tilted Lines)

\begin{tabular}{|c|c|c|c|c|c|c|}
\hline Group & $\begin{array}{c}\text { Mean } \\
\text { Illusion } C \\
\text { (Degrees) }\end{array}$ & $\begin{array}{c}\text { Linear } \\
\text { Component } \\
\text { (Tan. } \theta \text { ) }\end{array}$ & $\begin{array}{c}\text { Contrasts } \\
\text { (Means) }\end{array}$ & $\mathbf{F}$ & $\begin{array}{l}\text { Contrasts } \\
\text { (Linear } \\
\text { Component) }\end{array}$ & $\mathrm{F}$ \\
\hline $\begin{array}{r}22.5 \mathrm{deg} \\
45 \mathrm{deg}\end{array}$ & $\begin{array}{l}2.22 \\
0.46\end{array}$ & $\begin{array}{r}0.17 \\
-0.02\end{array}$ & $(22.5 \mathrm{deg})-(45 \mathrm{deg})^{*}$ & 15.27 & $(22.5 \mathrm{deg}-45 \mathrm{deg})^{*}$ & 13.69 \\
\hline $67.5 \mathrm{deg}$ & -2.95 & -0.14 & $(67.5 \mathrm{deg})-(45 \mathrm{deg}) *$ & 27.29 & $(67.5 \mathrm{deg}-45 \mathrm{deg})^{*}$ & 6.36 \\
\hline
\end{tabular}

df 1,36-MS between individual means (error) $=20.035$

MS between individual linear trend components (error) $=1.302$

* Contrasts significant at the 0.05 level

Critical value of $F_{0.05}=4.12$ 
The effects are markedly different in size, and there is no overlap in their distributions. A further interesting feature of this line-illusion data is that over the 10 trials, the effect grows as is shown by the statistically significant linear trends for tilts of 22.5 and $67.5 \mathrm{deg}$. This could be due to the prolonged exposure to the illusion involved in making 10 judgments (average time of exposure, $200 \mathrm{sec}$ ), although the mean illusion is somewhat larger than that generally found, and this could indicate a response persistence or learned effect similar to that found by Collins and Singer (1968).

It can be concluded, then, that neither the presence of familiar objects in the tilted room nor the presence of a larger number of vertical lines in the field are the determinants of the size of the illusion. However, it may be possible that, under some conditions (in this experiment, at $45 \mathrm{deg}$ ), an interaction of these two factors may increase the size and the rate of growth over time of the illusion. The results also indicate that these two factors cannot be the determinants of the illusion itself, as the maximum illusion is present with the room alone at rotations of 22.5 and $67.5 \mathrm{deg}$. Further, if it was argued that the only determinant of the illusion was the fact that the room contained at least four vertical contours that were tilted, one would expect as large or larger illusions with the tilted-line situation used in this experiment -20 vertical contours as against 4 in the room alone. As there was no overlap between the distributions of the two types of illusion (Experiments 1 and 2 ), and since the field with the larger number of lines caused the smaller illusions, it would appear that there are other factors that are the determinants of the illusion. As the most obvious difference between a tilted room and a tilted-line field is that one is three-dimensional and the other two-dimensional, it is proposed that this or associated factors may be the critical variables.

\section{REFERENCES}

ASCH, S. E. \& WITKIN, H. A. Studies in space orientation: I. Perception of the upright with displaced visual fields. Journal of Experimental Psychology, 1948a, 38, 325-337.

ASCH, S. E., \& WITKIN, H. A. Studies in space orientation: II. Perception of the upright with displaced visual fields and with body tilted. Journal of Experimental Psychology, 1948b, 38, 455-477.

AUSTIN, M., SINGER, G. \& DAY, R. H. A visual orientation illusion following judgments with a tilted visual field. Nature, 1969, 221, 583.

COLLINS, J. K., \& SINGER, G. Interaction between sensory spatial after-effects and persistence of response following behavioral compensation. Journal of Experimental Psychology, 1968, 77, 301-307.

GIBSON, J. J., \& RADNER, M. Adaptation, after-effect and contrast in the perception of tilted lines: 1. Quantitative studies. Journal of Experimental Psychology, 1937, 20, 453-467.

GRANT, D. A. Analysis of variance tests in the analysis and comparison of curves. Psychological Bulletin, 1956, 53, 141-154.

LOGAN, J. A. An examination of the relationship between visual illusions and figural after-effects. Unpublished doctoral dissertation, University of Sydney, 1962.

RODGER, R. S. Intermediate statistics. Sydney: University Co-operative Bookshop, 1965.

WITKIN, H. A., \& ASCH, S. E. Studies in space orientation: III. Perception of the upright in the absence of a visual field. Joumal of Experimental Psychology, 1948a, 38, 603-614.

WITKIN, H. A., \& ASCH, S. E. Studies in space orientation: IV. Further experiments on perception of the upright with displaced visual fields. Journal of Experimental Psychology, $1948 b, 38,762-782$.

\section{NOTES}

1. Address: Macquarie University, North Ryde, New South Wales 2113, Australia.

2. To maintain continuity in terminology with that employed by Gibson and Radner (1937), Asch and Witkin (1948a, b), and Austin et al (1969), "tilt" has again been used to refer to rotation away from the vertical in the frontal plane.

(Accepted for publication August 1, 1969.) 